\title{
LA CERÁMICA ESPAÑOLA EN EL COMERCIO MEDITERRÁNEO BAJOMEDIEVAL. ALGUNAS NOTAS DOCUMENTALES
}

\author{
Alberto García Porras* \\ Adela Fábregas García*
}

\section{RESUMEN}

El trabajo aborda el comercio de cerámica hispana bajomedieval en las ciudades italianas durante la Baja Edad Media. Se pretenden trazar las pautas de evolución de dicho comercio entre los siglos XII y XV. Para ello acudimos a metodologías de análisis combinados de informaciones arqueológicas y documentales procedentes de la Península Italiana. Observamos su llegada desde los principales centro de recepción y seguimos su rastro en las redes de distribución de los mercados italianos.

Con todo ello apuntamos tendencias de desarrollo hacia una diversificación morfológica de la cerámica importada y de centros productivos, con una importante referencia inicial a la producción en azul y dorado nazarí y una posterior sustitución de la misma por la producción valenciana. Asimismo se observa la fluidez que va alcanzando la circulación de estos materiales cerámicos entre los siglos XIV y XV, rebasando los estrechos límites de las ciudades comerciales italianas y alcanzando paulatinamente núcleos urbanos de menor entidad.

Palabras clave: Cerámica medieval. Comercio medieval. Reino nazarí de Granada. Valencia. Mercados italianos.

\section{ABSTRACT}

The paper covers Hispanic ceramic trade in the late Middle Ages in Italian cities. Our aim is to trace the development trend of that trade between the $12^{\text {th }}$ and the $15^{\text {th }}$ centuries and we have done this by using analysis methodologies combined with archaeological and documentary information from the Italian peninsula. We have observed its arrival at the main reception centres and followed its trail in the distribution networks of the Italian markets. As a result, we have noticed morphological diversification development trends in imported ceramics and in production centres, with an important initial reference to Nasrid blue and gilded production, which was later replaced by Valencian production. We have also observed

* Universidad de Granada. 
the fluidity in the circulation of these ceramic materials between the $14^{\text {th }}$ and the $15^{\text {th }}$ centuries, which extended beyond the narrow limits of the Italian trade cities to gradually reach urban areas of lesser importance.

Key words: Mediaeval ceramic. Mediaeval commerce Nasrid Kingdom of Granada. Valencia. Italian markets.

\section{INTRODUCCIÓN}

La presencia de cerámica procedente de la Península Ibérica en Italia está bien documentada desde antiguo. El interés que han suscitado estos materiales en Italia hunde sus raíces en la cultura tradicional del anticuariado. Y ello se debe, al igual que ocurrió con otros artículos, a que nos encontramos ante piezas que siempre fueron consideradas, desde el momento en que fueron adquiridas, objetos lujosos, procedentes de lugares relativamente lejanos y portadoras de decoraciones en gran medida exóticas.

$\mathrm{Al}$ abordar el estudio de estas cerámicas ha primado generalmente la perspectiva propia de la Historia del Arte y, en los últimos tiempos, de la Arqueología, sobre cualquier otro tipo de análisis. En el primer caso porque estos materiales presentan una cuidada decoración. En el segundo caso, porque su aparición en determinados contextos arqueológicos documentaba la frecuente circulación de estos productos cerámicos por los mercados medievales italianos. Desde este punto de vista la Arqueología estaba llamada a ser de nuevo el estímulo que pusiera de manifiesto las carencias existentes en algunos estudios que, como el de los intercambios comerciales, sólo de manera ocasional han integrado elementos o productos como éste que ahora nos ocupa.

Resulta, por tanto, el del comercio de la cerámica, un argumento digno de más atención que la prestada hasta el momento. No obstante debemos ser conscientes de que uno de los principales efectos distorsionantes en este estudio procede precisamente de la naturaleza de su objeto, lo que nos obliga a acercarnos a él con las debidas reservas. Nos referimos a un factor que, no por evidente, resulta menos conveniente de recordar. La Arqueología nos permite afirmar, para el caso italiano, que la importación de cerámicas procedentes de la Península Ibérica durante la Baja Edad Media era más capilar de lo que podría suponerse, pero corremos también el riesgo de obtener una imagen sobredimensionada del lugar que ocuparan estos productos en el espectro merceológico que componía el grueso de los intercambios comerciales entre los diversos territorios hispánicos e Italia. En este sentido consideramos muy apropiadas las reflexiones de algunos autores cuando señalan que «gli archeologi sono vittime di quella maledizione che è l'indistruttivilità dei cocci», que podría conducir a «sopravvalutare merci ingombranti, onnipresenti e non deperibili, come le ceramiche appunto, ma poco rilevanti, come pensava, nell'ambito delle economie antiche» ${ }^{1}$, aunque después se afirme que «gli archeologi hanno tuttavia bisogno di studiare

1 Sauro GELICHI: «Introduzione» en Sauro GELICHI (a cura di): Ceramiche, città e commerci nell'Italia Tardo-Medievale. Mantua, 1998, pp. 9-10, espc. p. 9. Recoge aquí una reflexión de M. Finley. 
le ceramiche, non solo per verificarne la rilevanza nell'ambito delle economie antiche o per tararne l'utilizzo come spia di rapporti commerciali, ma anche perche propio la loro abbondanza nelle stratigrafie li rende ottimi strumenti di datazione e indicatori di culture, gradi di tecnologia e status socio-economico» ${ }^{2}$. Es, por tanto, necesario hacer concurrir bajo un mismo objeto de estudio, en este caso la cerámica española importada en Italia durante la Baja Edad Media, datos procedentes de otras fuentes distintas a la arqueológica, con el objetivo de trazar en sus perfiles más próximos el hecho estudiado. En este sentido, la posibilidad de conjugar o confrontar estos dos ámbitos de información, a saber, la documentación escrita que hace referencia al tránsito comercial, relativamente abundante para la época que analizamos, con los datos que poseemos procedentes de los estudios arqueológicos, nos ha parecido un modo apropiado de acercamiento al tema.

No son muy numerosos los trabajos que han abordado el estudio de las cerámicas españolas llegadas a Italia desde la perspectiva que les ofrece la documentación escrita, algo que, sin embargo, no podemos decir de los estrictamente arqueológicos ${ }^{3}$. Algunos investigadores italianos ya cayeron en la cuenta de la importancia que presentaban los datos documentales referentes a estas cerámicas y la necesidad de abordar un estudio profundo y particular sobre este aspecto ${ }^{4}$. A Spallanzani se debe en gran parte el inicio de los estudios sobre cerámica ispano-moresca basándose en documentación escrita, procedente, en concreto, del archivo de la compañía de Francesco Datini de Prato 5 .

Por lo que se refiere a España, el interés suscitado por el estudio de los documentos que aluden a la cerámica de la que nos ocupamos comenzó antes. Aunque los inicios son seguramente anteriores, podrían entenderse los trabajos de De Osma, realizados a principios del siglo XX, como los pioneros en este campo ${ }^{6}$, seguidos posteriormente por Van de Put, Gonzalez Martí y Olivar Daydí. En estos estudios se hacía especial hincapié

2 Sauro GELICHI: Introduzione all'Archeologia Medievale. Storia e ricerca in Italia. Roma, 1997, p. 207.

3 Los estudios sobre cerámica española en Italia son muy numerosos. Destacaremos de entre estos últimos, por ser los más recientes y los que han tratado el tema de manera más global, los de Riccardo FRANCOVICH, Sauro GELICHI: «La ceramica spagnola in Toscana nel Bassomedioevo». Quaderni dell'Insegnamento di Archeologia Medievale della Facoltà di Lettere e Filosofia dell'Università di Siena, 3 (1984); Graziella BERTI, Ezio TONGIORGI: «Ceramiche importate dalla Spagna nell'area pisana dal XII al XV secolo». Quaderni dell'Insegnamento di Archeologia Medievale della Facoltà di Lettere e Filosofia dell'Università di Siena, 6 (1985); Carmen RAVANELLI GUIDOTTI: Mediterraneum. Ceramica spagnola in Italia tra Medievo e Rinascimento. Viterbo, 1992.

4 Marco SPALLANZANI: Ceramiche orientali a Firenze nel Rinascimento. Florencia, 1978 (reed. 1997), no se ocupa de la cerámica española, aunque señala que «...la maiolica ispano-moresca, che sotto molti aspetti potrebbe e dovrebbe essere inclusa, viene in questa sede totalmente trascurata, in conseguenza non tanto della gran quantità di materiale archivistico reperito (che imporrebbe un'indagine diversa), quanto del carattere tutto particulare che l'importazione a Firenze della maiolica spagnola appunto presenta..», p. 13.

5 Marco SPALLANZANI: «Un invio di maioliche ispano-moresche a Venezia negli anni 1401-1402». Archeologia Medievale, V (1978), pp. 529-541; Marco SPALLANZANI «Maioliche di Valenza e di Montelupo in una casa pisana del 1480». Faenza, LXXII (1986), n³ 3-4, pp. 164-170.

6 Guillermo J. DE OSMA: La loza dorada de Manises en el año 1454 (Cartas de la Reina de Aragón a Don Pedro Boil). Madrid, 1906; IDEM: Las divisas del Rey en los pavimentos de «obra de Manises» del Castillo de Nápoles. (años 1446-1458). Madrid, 1909 y Los maestros alfareros de Manises, Paterna y Valencia. Contratos y ordenanzas de los siglos XIV, XV y XVI. Madrid, 1923. 
en ciertos aspectos que ya mostraban la dificultad de trasladar los datos aportados por los documentos al conocimiento que hasta el momento se tenía de las cerámicas a las que se referían ${ }^{7}$. Quizá estas dificultades motivaron el abandono paulatino de esta línea de trabajo, que parecía mostrar ciertos síntomas de agotamiento. Han debido pasar varias décadas y, sobre todo, ha sido necesario abordar el estudio de la cerámica bajomedieval española desde otra perspectiva, esencialmente arqueológica, para que de nuevo resultaran interesantes los datos sugeridos por las fuentes escritas. En efecto, en los últimos años ha vuelto a retomarse el tema, aunque sólo de manera ocasional. A mediados de los años 80 lo hizo López Elum con el estudio de un grupo de protocolos notariales valencianos, abordando algunas de las cuestiones que ya había tratado en su día De Osma ${ }^{8}$. Recientemente, a mediados de los años noventa, se han vuelto a realizar algunos trabajos basados en documentación escrita ${ }^{9}$.

Nuestro trabajo, debido en parte al origen de las fuentes a que hemos recurrido, puede incluirse más dentro de la línea italiana, que afronta la cuestión desde el enfoque que ofrecen los centros de recepción y redistribución de estas piezas, que en la española, que se ocupa fundamentalmente de los centros productores, su cronología y las características tanto decorativas como morfológicas de las vasijas. Por tanto las informaciones de que disponemos pueden ser tan interesantes en algunos aspectos como decepcionantes en otros, sobre todo en cuanto a detalles concernientes al proceso y dinámica productiva. Somos conscientes en todo caso de que estas imágenes «invertidas» de un mismo proceso no sólo resultan compatibles si no del todo complementarias, y que el deber de conjugarlas, o intentarlo al menos, es insoslayable en este ejercicio de análisis de un fenómeno único: el del comercio de cerámica hispana bajomedieval en las ciudades italianas.

La cerámica procedente de la Península Ibérica que llevaba un revestimiento vítreo y una decoración relativamente compleja comenzó a introducirse en Italia ya a lo largo del siglo XII. Uno de los primeros testimonios de este comercio de cerámica lo hallamos precisamente en una anotación documental. A mediados del siglo XII un testamento de una modesta familia mercantil genovesa señala entre sus posesiones unam scutellam pictam de Almeria $^{10}$. La anotación es bastante imprecisa, no tanto respecto a la forma de la pieza, que debió ser una escudilla o un plato de pequeñas dimensiones, cuanto a la decoración que

7 Marçal OLIVAR DAYDÍ: La ceramica trecentista en los paises de la Corona de Aragón. Barcelona, 1952; Manuel GONZÁLEZ MARTÍ: Cerámica del Levante español. Siglos medievales. vol. I. Loza. Barcelona, 1944; Albert VAN DE PUT: Hispano-Moresque ware of the XV. Century. A contribution to its history and chronology based upon armorial specimens. Londres, 1904; IDEM: Hispano-moresque ware of the fifteenth century. Supplementary studies and some later examples. Londres, 1912, y The Valencian styles of Hispano-Moresque pottery. 1404-1454. Nueva York, 1938.

8 Pedro LÓPEZ ELUM: Los orígenes de la cerámica de Manises y Paterna (1285-1335). Valencia, 1984, y «Origen y evolución de dos grandes centros cerámicos: Manises y Paterna». La ceramica medievale nel Mediterraneo Occidentale. Florencia, 1986, pp. 163-181.

9 Maria BARCELÓ CRESPÍ, Guillem ROSSELLÓ BORDOY: Terrissa. Dades documentals pera l'estudi de la ceràmica mallorquina del segle XV. Palma de Mallorca, 1996.

10 Es el testamento de Raimondo Pictenado, redactado en 1156, fol. 5 r. Edit en Mario CHIAUDIANO, Mattia MORESCO: Il cartolare di Giovanni Scriba. Turín, 1935, 2 vols. Vol I, pp. 23-25, espec. p. 25. A él se refiere también Tiziano MANNONI: «La ceramica medievale a Genova e nella Liguria». Studi Genuensi, VII (1968/69), p. 173. 
lucía. Por otro lado esta vaguedad nos impide indicar el tipo de técnica empleada, ya que del motivo decorativo nada se dice. No obstante el tema ha sido tratado por algunos autores, y aun cuando se ocupaban de una época posterior y se basaban en documentación escrita distinta a la nuestra, en concreto a los primeros contratos con alfareros sellados en el área valenciana ${ }^{11}$, sus conclusiones pueden ser válidas o al menos tenidas en cuenta también en este caso. Las interpretaciones han sido variadas en relación al significado del término pictum, en sus diversas variantes. Recientemente parece haberse llegado a un acuerdo, según el cual el uso de este término en los documentos se refiere a las labores decoradas con dorado ${ }^{12}$, en concreto a la denominada «loza dorada». Las extrapolaciones resultan particularmente arriesgadas en este caso, ya sea por las distintas fechas en las que fueron redactados los documentos, ya sea por la distancia existente entre los lugares y los contextos en que fueron generados. Al margen de estas prudentes reservas, sí parece claro que una de las primeras producciones cerámicas medievales de lujo que llegó a Italia procedente de al-Andalus fue la «loza dorada». En efecto, para esta época la producción de cerámica lustrada en al-Andalus parece estar ya claramente consolidada ${ }^{13}$, elaborando unas decoraciones diferenciadas y que eran ya reconocidas como propias fuera de las fronteras peninsulares ${ }^{14}$. Italia debió ser uno de los destinos de exportación. De hecho, muchas de estas piezas decoradas con dorado fueron utilizadas para la decoración mural de las fachadas y campanarios de las iglesias de la zona centro-septentrional de la Península italiana. Entre ellos destacan los de S. Apollinare Nuovo, en Rávena ${ }^{15}$, o algunos de los hallados en Pisa ${ }^{16}$, entre otros.

El camino de estas importaciones ibéricas seguramente fue abierto por otros conjuntos decorados con técnicas como el «verde y morado» ${ }^{17}$, la «cuerda seca» ${ }^{18}$ o algunos estampillados bajo cubierta vítrea que llegaron a Italia poco antes. Estas piezas lustradas aprovecharon las corrientes abiertas por sus antecesoras, llegando a sustituir a las cerámicas doradas tradicionalmente venidas de otros centros del Mediterráneo oriental. De este modo, comienzan a presentarse a finales del XI o principios del XII y se continúan importando hasta la primera mitad del XIII. Como puede observarse, los testimonios proceden fundamentalmente de los denominados bacini, aunque algunas excavaciones arqueológicas han

11 Véase Guillermo J. DE OSMA: Los maestros alfareros..., pp. 18-19. Véase también Marçal OLIVAR DAYDÍ: La ceramica trecentista..., pp. 104-120.

12 Una síntesis de la evolución de la interpretación del término, junto a una consideración concluyente en Pedro LÓPEZ ELUM: Los orígenes de la cerámica..., pp. 30-34.

13 Balbina MARTÍNEZ CAVIRÓ: La loza dorada. Madrid, 1982, pp. 46-48.

14 AL-IDRĪSĪ: Description de l'Afrique et de l'Espagne. Reinhart DOZY, Michael J. de GOEJE (eds.), Amsterdand, 1969, p. 189 del texto árabe, p. 230 de la traducción francesa. Hace referencia a Calatayud.

15 Gaetano BALLARDINI: «Alcuni cenni sulla ceramica orientale, con particolare riguardo alla ispanomoresca (a proposito dei «bacini» di S. Apollinare Nuovo di Ravenna)». Faenza, (numero commemorativo del primo decennio dalla fondazione del Museo 1908-1918) 1919, pp. 33-40.

16 Graziella BERTI, Liana TONGIORGI: «I bacini ceramici medievali delle chiese di Pisa». Quaderni di Cultura Materiale, 3 (1981), pp. 262-266.

17 Graziella BERTI, Tiziano MANNONI: «Céramiques de l'Andalusie décorées en «verde y manganeso» parmi les «bacini» de Pise de la fin du Xe siècle». La Céramique Médiévale en Méditerranée. Actes du VIe Congrès de l'AIECM2. Aix-en-Provence, 1997, pp. 435-437.

18 Graziella BERTI, Tiziano MANNONI: «Le ceramiche a "cuerda seca" utilizzate come "bacini” in Toscana e in Corsica». Actes du 5éme colloque sur la céramique médiévale en Mediterranée Occidentale. Rabat, 1995, pp. 400-404, y Tiziano MANNONI: La ceramica medievale..., p. 102, tipo 80. 
demostrado la presencia en contextos domésticos contemporáneos de estas mismas series ${ }^{19}$. En cualquier caso los lugares donde éstas han aparecido, esencialmente Liguria (Savona y Génova) y Toscana (Pisa), así como los ambientes donde han sido encontrados, nos señalan que su distribución estuvo restringida a aquellas ciudades y territorios circundantes, donde las actividades comerciales se desarrollaron de manera más prematura, y dentro de ellas en contextos relativamente privilegiados ${ }^{20}$.

Este marco general parece, sin embargo, verse modificado en los últimos siglos de la Edad Media. Durante todo el siglo XIII y especialmente hacia su final y principios del XIV, la importación de materiales cerámicos procedentes de la Península Ibérica experimenta un cambio sustancial. Este cambio puede analizarse desde la doble perspectiva que aportan los conocimientos relativos a las áreas de producción y las áreas de recepción.

En primer lugar, por lo que respecta a las áreas productivas, se observa la interacción de dos fenómenos complementarios. Por un lado la producción cerámica andalusí mantiene en líneas generales las pautas ya desarrolladas por las producciones anteriores. Podría señalarse, a lo sumo, que la producción dorada y azul y dorada de finales del siglo XIII y principios del XIV, que podría considerarse la más precoz producción cerámica de lujo nazarí, experimenta un matizado desarrollo y crecimiento con relación a la etapa anterior. Por otro lado, desde finales del siglo XIII se produce la irrupción en los mercados de la producción cerámica elaborada en el territorio más próximo a la ciudad de Valencia. Además, como se ha puesto de relieve en diferentes estudios, el fenómeno se ve acompañado de una capacidad productiva y de distribución comercial desconocida hasta entonces. Dos conjuntos en concreto parecen ser protagonistas del cambio que marca la producción cerámica valenciana: el estilo conocido como «malagueño» y el denominado «tipo Pula» ${ }^{21}$. La filiación valenciana de estas piezas está fuera de toda duda ${ }^{22}$, y después de observar el modo en que ocupó los circuitos comerciales por donde circularía, bien podría pensarse que en su «repentino» origen pudo tener gran trascendencia la vertiente comercial que ya anunciaban sus predecesoras y contemporáneas islámicas.

Por lo que respecta a las áreas de recepción, las ciudades italianas, en este período se constata, y no de manera indiferente, una transferencia de conocimientos técnicos alfareros procedentes de diversas áreas del Mediterráneo. Este proceso de cambio y transformación tecnológica parece observarse con mayor claridad en ciudades de la trascendencia en nuestro

19 Graziella BERTI: «Ceramiche islamiche (IS). $2^{\circ}$ m. X-m. XIII», en Stefano BRUNI (a cura di): Piazza Dante. Uno spaccato della storia pisana. La campagna di scavo 1991. Pontedera, 1993, pp. 535-582.

20 Véase el caso de Génova en Danilo CABONA, Alexandre GARDINI, Tiziano MANNONI, Marco MILANESE: «Ulteriori contributi dell'archeologia medievale ligure sulla diffusione dei prodotti ceramici nel Mediterraneo Occidentale». La céramique médiévale en Mediterranée Occidentale. París, 1980, pp. 113-123, espec. p. 117.

21 Los trabajos dedicados a este tipo de cerámica son múltiples; entre ellos Graziella BERTI, Liana TONGIORGI: «I bacini ceramici delle chiese della provincia di Pisa con nuove proposte per la datazione della ceramica spagnola «tipo Pula»». Faenza, LX (1974), pp. 67-79; Hugo BLAKE: «The ceramic hoard from Pula (prov. Cagliari) and the Pula type of Spanish lustreware». Segundo Coloquio Internacional de Cerámica Medieval en el Mediterráneo Occidental. Madrid, 1986, pp. 365-405.

22 Hugo, BLAKE, Michael HUGHES, Tiziano MANNONI, Francesca PORCELLA: «The earliest valencian lustreware? The provenance of the pottery from Pula in Sardinia», en Everyday and exotic pottery from Europe. C. 650-1900. Studies in honour of John G. Hurst. Oxford, 1992, pp. 202-224. 
estudio de Pisa, Savona o Venecia ${ }^{23}$, en donde entre 1210 y 1230 comienzan a producirse las primeras cerámicas italianas esmaltadas y decoradas en verde y morado, la denominada maiolica arcaica $^{24}$, y los más tempranos ejemplares con engobe pintado y esgrafiado ${ }^{25}$.

Este contexto de desarrollo de la producción de cerámicas esmaltadas en ambas penínsulas, y en general en todo el Occidente europeo, favoreció el auge de su intercambio. Para la introducción de las cerámicas pertenecientes a los estilos «malagueño» y «Pula», los comerciantes debieron servirse de los mismos mecanismos y las mismas vías utilizadas hasta entonces en la distribución de los productos cerámicos andalusíes en Italia. Si observamos los puntos de recepción de los ejemplares citados y los lugares en donde han aparecido piezas o fragmentos valencianos de los estilos «malagueño» y «Pula», se podrá concluir sin grandes dificultades que éstas alcanzaron los lugares implicados ya en un fluido intercambio cerámico con aquéllas. Varía, eso sí, la intensidad del fenómeno, ya que el volumen de material cerámico encontrado se vio claramente acrecentado, y el alcance territorial se vio igualmente aumentado, ya que las piezas pertenecientes a estos grupos alcanzaron localidades que, aunque próximas a las primeras ciudades comerciales que introdujeron piezas procedentes de los territorios islámicos peninsulares, documentaban por primera vez la existencia de piezas hispánicas importadas.

Si tomamos como ejemplo la Liguria, región que se vio tempranamente implicada en la importación de productos cerámicos procedentes de la Península Ibérica, este fenómeno se observa en sus aspectos más particulares ${ }^{26}$. Si bien este tipo de piezas llegó esencialmente a las ciudades lígures más importantes y a su entorno más inmediato, en especial Génova y Savona, aunque no debemos olvidarnos de ciertas localidades del Poniente, como Finalborgo, con estos nuevos productos cerámicos se documenta una clara extensión de su radio de penetración, viéndose afectadas ahora localidades de rango menor. Se diversificó también su uso, que comprendería fines eminentemente decorativos en las fachadas de algunas iglesias, como es el caso del magnífico conjunto de San Ambrosio Nuevo en Varazze $(\mathrm{SV})^{27}$. No desdeñó tampoco su presencia en el ámbito doméstico, tal y como han puesto de manifiesto excavaciones llevadas a cabo en contextos de este tipo ${ }^{28}$. Todo ello

23 Graziella BERTI, Sauro GELICHI: «Trasmissioni di tecnologie nel medioevo: tendenze e linee di ricerca attuali». XXXII Convegno Internazionale della ceramica. Albisola, 2001, pp. 23-41; y Graziella BERTI, Sauro GELICHI: «Ceramiche, ceramisti e trasmissioni tecnologiche tra XII e XIII secolo nell'Italia centro settentrionale». Miscellanea in Memoria di Giuliano Cremonesi. Pisa, 1995, pp. 409-445.

24 Graziella BERTI: Pisa. Le "maioliche arcaiche”. Secc. XIII-XV (Museo Nazionale di San Matteo), con apéndice de Catia RENZI RIZZO: “"Nomina Vasorum”. Indagine storico-linguistica sulle denominazioni dei manufatti ceramici a Pisa nei secoli VIII-XVIII». Florencia, 1997.

25 Sauro GELICHI: Introduzione all'Archeologia..., pp. 224-229.

26 Alberto GARCÍA PORRAS: «La cerámica esmaltada procedente de la Península Ibérica importada en Italia. El caso de la Liguria del Poniente», en Actas del coloquio De la céramique à l'Histoire celebrado en Perpiñán entre el 21 y 24 de noviembre de 2000 (en prensa).

27 Hugo BLAKE: «I bacini del campanile di S. Ambrogio a Varezze». Quaderno ligustico (estratto del Bolletino Ligustico), 3/4 XXII (1972), pp. 130-136, y Hugo BLAKE: «La ceramica medievale spagnola e la Liguria». V Convegno internazionale della ceramica. Albisola, 1972, pp. 55-91.

28 Sonia GOBBATO: «La circolazione delle maioliche medievali di produzione spagnola nella Liguria di ponente tra XIII e XV secolo. Gli esempi di Savona e Albenga». XXXI Convegno internazionale della ceramica. Albisola, 1999, pp. 285-293. 
nos indica que es precisamente en estos momentos, finales del siglo XIII y primera mitad del XIV, y especialmente con estas producciones, cuando se asiste al incremento de la demanda de productos cerámicos esmaltados hispánicos en Italia.

Esta alta demanda comenzó incluso a influir sobre los procesos productivos en los lugares de origen. Algunos rasgos morfológicos de ciertos tipos cerámicos comprendidos en este amplio conjunto de piezas parecen ser inéditos si se ponen en relación con la producción cerámica anterior. Esto se observa especialmente entre los ejemplares de origen nazarí hallados en Italia, ya que este grupo observa una cierta continuidad morfológica y productiva a lo largo del siglo XIII en su área de origen. No obstante, se constata la irrupción de algunos elementos formales nuevos tales como el ala empleada en algunos platos o ataifores, que son, recordémoslo, piezas con un destino comercial más claro. Pero curiosamente estas novedades aparecen en contextos cristianos, donde se suelen aplicar en piezas esmaltadas o engobadas. A nuestro entender, la presencia de estos nuevos elementos sugiere la posibilidad de que fueran adoptados por los alfareros nazaríes, con el fin de satisfacer las exigencias impuestas por el comercio de estos materiales.

Las producciones cerámicas valencianas decoradas en azul y dorado que siguieron al estilo «malagueño»y al tipo «Pula», sin menoscabo de que se exportaran en algunos momentos de manera simultánea con las nazaríes, presentan unos rasgos más cercanos al estilo gótico imperante en el resto de Europa. Los ejemplares que presentaban motivos de carácter vegetal, tales como la hoja de perejil, de bryonia o de yedra, o las que tenían motivos más claramente góticos, como los letreros o los escudos, alcanzaron un gran éxito en Italia. En cualquier caso, las decoraciones que presentan estas piezas nunca perdieron cierta inspiración islámica, procedente seguramente del medio social en que fueron producidas, que les permitían mantener ciertos caracteres específicos o particulares que las hacían reconocibles como de origen gótico-mudéjar, favoreciendo de este modo su salida comercial. Nos referimos en concreto a las piezas correspondientes a los denominados estilos «clásico»y «maduro», y a sus distintas familias decorativas ${ }^{29}$.

La importación de esta amplia y compleja familia cerámica, que comenzó a salir de los alfares valencianos a mediados del siglo XIV y se mantuvo en plena vigencia de elaboración durante todo el siglo XV, llegó a adquirir en Italia niveles muy considerables. Se han localizado piezas a lo largo y ancho de la geografía italiana, alcanzando incluso lugares donde esta cerámica era, hasta el momento, desconocida, ya fuera por su distancia respecto a los puertos de entrada, o bien por el contexto económico o social que podía haberlas solicitado ${ }^{30}$. Ya señalamos que las cerámicas nazaríes y las primeras producciones valencianas en su momento pudieron alcanzar localidades de rango menor. El conjunto que ahora nos ocupa se ha llegado a documentar en excavaciones realizadas en castillos de carácter feudal o en localidades pequeñas de vocación eminentemente rural; en todos los casos relativamente alejados de los centros por donde estas piezas eran introducidas en Italia.

29 Sobre estas cerámicas se ha escrito mucho, aunque todavía mantiene gran validez el trabajo realizado por Manuel GONZÁLEZ MARTÍ: Cerámica del Levante español..., junto al de Juan AINAUD de LASARTE: Cerámica y vidrio. col. Ars Hispaniae, vol. X, Madrid, 1952, y Ma Paz SOLER FERRER: Historia de la cerámica valenciana. Valencia, 1988.

30 Véase Carmen RAVANELLI GUIDOTI: Mediterraneum... 
Podría considerarse, por tanto, la importación de estos materiales como de proporciones considerables y distribución capilar. De hecho, no se van a ver implicadas solamente las regiones centro-septentrionales de la Península, además de Sicilia y Cerdeña, zonas que tradicionalmente se han considerado como las más afectadas por la importación de cerámicas esmaltadas españolas. Ahora se documentan también en el área meridional de la Península ${ }^{31}$. Parece claro que la incorporación de estos territorios a la Corona de Aragón, como ocurrió con determinadas zonas del suroeste de Francia ${ }^{32}$, debió desempeñar un papel de primer orden para explicar la llegada de estos materiales al Mezzogiorno. Es este último tipo de cerámica al que se deben referir en mayor medida los documentos de los que nos ocuparemos a continuación.

Las décadas finales del siglo XV y las iniciales del XVI muestran la decadencia comercial de las cerámicas elaboradas en el área valenciana. Varios motivos podrían argüirse para explicar este fenómeno. Algunos factores deben considerarse internos a la producción cerámica valenciana; otros, derivados de las producciones contemporáneas italianas. Ambos, en cualquier caso interrelacionados. Si se observa el desarrollo decorativo de la cerámica valenciana, se verá con claridad que la tendencia al abigarramiento se fue acentuando a lo largo de la segunda mitad del siglo, alcanzando altos niveles de barroquismo. Al mismo tiempo, en las producciones esmaltadas italianas comenzó a primar un nuevo concepto ornamental, vinculado a las tendencias artísticas del momento. Se asiste al nacimiento de la maiolica rinascimentale, más cercana a los gustos de la aristocracia y burguesía bajomedieval y moderna. El resultado de todo ello se tradujo en un debilitamiento claro del impulso comercial en la cerámica valenciana, junto a un desarrollo creciente de la cerámica esmaltada bajomedieval italiana, ésta última llamada a tomar el relevo de aquélla en el mercado cerámico europeo ${ }^{33}$.

\section{EL ESTUDIO DOCUMENTAL}

Pasamos en adelante a presentar los datos que nos aportan los documentos que hemos manejado. Han sido recogidos prevalentemente en el ya explorado por otros y siempre rico en novedades archivo de la Compañía Datini de Prato. A ellos acompañan otras informaciones procedentes de fuentes diversas y en algunos casos ya conocidas. No se ha tratado de una exploración sistemática y por lo tanto las conclusiones a que llegamos no pueden ser entendidas como definitivas, aunque sí creemos que pueden definir ciertas líneas tendenciales dignas de ser tomadas en consideración. La consulta se ha centrado

31 Riccardo FRANCOVICH, Sauro GELICHI: La ceramica spagnola..., p. 19. Hugo BLAKE: La ceramica medievale..., pp. 80-83.

32 François AMIGUES: La Céramique émaillée: témoin des relations entre le Languedoc-Roussillon, la Catalogne et le Pays valencien (XIVe, XVe, XVIe siècles). 2 vols. Montpellier, 1984 y «Las importaciones de cerámicas doradas valencianas de los talleres de Paterna en Languedoc-Rossellón», en Mercedes MESQUIDA GARCÍA (dir.): La cerámica de Paterna. Reflejos del Mediterráneo. Valencia, 2002, pp. 58-82.

33 Relevo visible también en otras regiones europeas permeables al comercio cerámico. Véase Henri AMOURIC, Florence RICHEZ, Lucy VALLAURI: Le commerce de la céramique en Provence et Languedoc du Xe au XIXe siècle. Vingt mille pots sous les mers. Aix-en Provence, 1999, pp. 56-78, incluido el granadino. Raffaella CARTA: Cerámica italiana en la Alhambra. Granada 2003. 
básicamente en la correspondencia mantenida con o desde Valencia, aunque ésta tampoco ha sido rastreada en su totalidad. En todo caso quedaron cubiertas las relaciones con Lucca (filza 994), Savona (filza 1003), Pisa (filza 547), Ibiza (filza 1084), parte de Génova (filza 795) y parte de Barcelona (filza/s 915, 919, 921, 923, 924 y 925). Han sido consultados también los cargamentos de naves y mercuriales custodiados en la filza 1171, además de las aseguraciones recogidas en las filza/s 1158, 1159 y 1160, y por supuesto conocemos en su totalidad la escasa correspondencia mantenida con el reino nazarí de Granada, aunque sea sólo para constatar el nulo interés que despierta aquí este tipo de operaciones. Dista mucho, por tanto, de ser una labor concluida, lo cual debe quedar presente en todo momento. Repetimos, no obstante, el interés que han suscitado en nosotros esta serie de hallazgos «fortuitos», sobre todo porque constituyen un prometedor anuncio de cuánto podría aportar al tema un trabajo sistemático.

El conjunto de datos recogidos o conocidos del Datini arroja un total de 27 operaciones de compra o envío de cerámica a mercados o mercaderes italianos, en un arco de tiempo comprendido entre los años 1383 y 1407. Abarca, por tanto, un segmento considerable del ciclo de vida de la compañía de Prato, que, recordemos, estuvo activa desde 1365 hasta 1412, poco después de la muerte de su fundador, Francesco di Marco Datini. Evidentemente el comercio con cerámica no es una actividad ni mucho menos relevante, sobre todo si la comparamos con los montantes y empeño que se dedican a otras facetas del comercio, incluso en este área valenciana. Teniendo en cuenta la procedencia de los cargamentos, éstos no constituyen una excepción a la norma de la zona y de la compañía con que tratamos. La lana es el artículo prevalente, con un amplio margen de ventaja sobre el resto de mercancías transportadas ${ }^{34}$. En los cargamentos de las naves que nos han llegado con aclaración de su procedencia ${ }^{35}$, las 21 y 5 tinajas de cerámica acompañan a 13.240 fardos y 1.532 fajos de lana respectivamente, además de productos laneros de segunda categoría como vellón (212/495 fajos), estambre ( 2 balas), pieles de cordero (21/87 balas) y de cabra (28/104 fajos), paños (140/11 balas), y ya en cantidades menores cueros y cordobanes, seda, productos alimenticios como arroz, anchoas y sardinas, almendras, dátiles e higos, mantequilla, especias como anís o comino, productos tintóreos como grana, quermés o azafrán y otros artículos, también minoritarios, como pergaminos, cuerdas, velas, sevo, pez o barniz. En cuanto a los cargamentos que no especifican su procedencia ${ }^{36}$, presentan sin embargo una índole fácilmente reconocible y adscribible a las mismas regiones, caso de la mayoritaria presencia de lanas (1.959/ 1.499 fardos y sacas respectivamente) y una identificación casi total con el resto de mercancías transportadas en los viajes mejor conocidos.

Es la representación a gran escala de lo que acontece en el ámbito de las operaciones individuales de esta compañía en concreto, aunque seguramente extensibles a los intereses de los mercaderes extranjeros en la zona. Efectivamente, cuando disponemos de este tipo

34 P. López Elum llegó incluso a observar cierta conexión entre los sectores textil y alfarero valencianos en relación con la distribución y comercialización de los productos cerámicos. Pedro LÓPEZ ELUM: Origen y evolución..., pp. 169 y 180.

35 Archivo di State di Piato, Arvhivo Datini, Filza 1171, fasc. II/1, fol. 90 (s.a., 26/I). Cargamento de 4 naves de Cataluña a Porto Pisano) y fasc. II/2, fol. 6 v. (1396-23-IV. Cargamento de 2 naves de catalanes de Valencia a Barcelona.

36 Ibidem, fasc. II/2, fol. 14 v.-15 r. (1396/5/XII) y fasc. II/2 fol. 15 r. (1396/5/XII). 
de información, aparece en clara sintonía con las tendencias generales. Cuando en 1394 Luca del Sera envía a la hacienda pisana 2 tinajas de cerámica y 13 piezas entre bacini y platos con tapadera, lo hace en una partida que incluye 120 sacas de lana de Castilla, 73 sacas de lana de Aragón, 33 sacas de lana de Aragón y 2 balas de añinos ${ }^{37}$. En 1401 la cerámica enviada nuevamente a Pisa acompaña un cargamento más voluminoso de cueros ( 38 fajos de diversas procedencias), grana berberisca ( 5 balas grandes) y añinos ( 2 balas $)^{38}$. Finalmente en 1406 se envía un cofán de cerámica junto a 663 sacas de lana, 1 bala de grana, 1 bala de paños, 2 aludas de azafrán y 16 fajos de cuero ${ }^{39}$.

Todo ello no es óbice para dejar de constatar que, aún como actividad muy subsidiaria, es practicada con cierta asiduidad. Dado el origen de la documentación estudiada, lógicamente la mayoría de las informaciones hacen una clara referencia a Valencia como centro donde se realizaban las operaciones y por donde salían los artículos, aunque el lugar de producción estuviera algo distante de la ciudad. Ya hemos anunciado que la producción granadina no aparece reflejada en la documentación Datini de estos momentos, o al menos en aquélla a la que hemos tenido acceso. Todo ello evidentemente no quiere decir ni mucho menos que no participe de las tendencias de intercambio entonces activas, ya que tanto los trabajos arqueológicos mencionados, como otros datos documentales, alguno de ellos ya citado, señalan con claridad la circulación de cerámicas nazaríes por diversos puntos del Mediterráneo e incluso del Mar del Norte. Quedaría por aclarar, por tanto, de qué modo las vasijas elaboradas en el reino de Granada eran introducidas en los circuitos comerciales. Estudiaremos los datos ofrecidos por los documentos, en primer lugar, en relación con su posible lugar de procedencia.

\section{La «Loza de Málaga»}

Son pocas las referencias documentales de que disponemos por el momento acerca de este tema. Algunas de ellas, por lo demás, son ya conocidas. Aún así cabría resaltar dos aspectos a nuestro juicio interesantes. En primer lugar las fechas. Las pocas noticias seguras que podemos utilizar, entre ellas la ya mencionada referencia a «...unam scutellam pictam de Almeria...», apoyan la impresión de que el comercio con cerámica nazarí fue un fenómeno que precedió al que tuvo como objeto la cerámica valenciana ${ }^{40}$. Los datos aportados por algunas excavaciones arqueológicas realizadas en Italia parecen confirmarlo a través del estudio de algunas secuencias estratigráficas, que señalarían que las cerámicas nazaríes circularon por los mercados italianos con anterioridad a las valencianas ${ }^{41}$.

37 A.S.P., A.D., Filza 547, Valencia-Pisa, doc. 600367 (1394/7/IX).

38 Ibidem, doc. $600230(1401 / 28 / \mathrm{V})$.

39 Ibidem, doc. 600214 (1406/8/XII).

40 G. Rebora señalaba que «i vasi di Malaga compaiono, infatti, già nel XIII ed agli inizi del XIV secolo, in testamenti ed inventari di farmacia», aunque, por desgracia, no hacía referencia precisa de los documentos. Giovanni REBORA: «La ceramica nel commercio genovese alla fine del Medioevo». Studi Genuensi, IX (1972), pp. 87-93, espec. p. 88 .

41 Extremo, éste, que hemos tenido la oportunidad de constatar directamente. Alberto GARCÍA PORRAS: «La presenza di ceramica bassomedievale spagnola nella Liguria di Ponente: Finalborgo e i castelli di Andora e Spotorno». XXXIV Convegno Internazionale della ceramica. Albisola, 2002, pp. 143-148, espec. p. 145. 
Las restantes referencias documentales, que por lo demás no especifican claramente que se trate de cerámica nazarí, por cuanto vienen recogidas bajo la voz genérica de Yspania, corresponden a los registros aduaneros de Génova relativos a los años 1376 y 1377. A partir de este momento, las escasas y muy posteriores ocasiones (1455 y 1458) en que las aduanas genovesas dan cuenta de entradas de cerámicas peninsulares ${ }^{42}$, especifican claramente que se trata de cerámica procedente de Valencia y, por supuesto, todo el arco temporal cubierto por la documentación Datini, más cercano a aquellas declaraciones de 1376 y 1377, se refiere siempre a cerámica valenciana. De ahí que otras noticias que se podrían considerar de adjudicación dudosa, como los dos cargamentos de naves de Giovanni di Negro y Giuliano da Mare, procedentes de Flandes y con destino final Génova tocando las costas españolas, sin más aclaración ${ }^{43}$, o los 7 cofres de potes pintados que realizan en 1404 el trayecto Málaga-Almería-Valencia-Barcelona ${ }^{44}$, no hayan sido finalmente incluidas en los grupos de cerámica nazarí. Creemos seguir con ello la lógica marcada por la documentación y mantener un ejercicio de prudencia.

No deja, sin embargo, de existir tráfico de cerámica granadina siquiera en estos momentos más tardíos; pero parece mantener, eso sí, una dirección diversa. Algo más numerosos, aunque tampoco abrumadores ni mucho menos, son los testimonios de transportes de loza granadina en dirección al norte de África. Un documento ya estudiado y publicado nos describe un trayecto practicado en 1344 por Antonio Janovi, que dirige su leño a Ceuta cargado con dos costales de «loza malagueña» ${ }^{45}$, vía comercial aún en funcionamiento, al parecer, durante la primera mitad del siglo XV, tal y como testimonia Gomes Eanes de Zurara ${ }^{46}$.

Estos datos nos parecen de especial interés para intentar conocer las causas que pudieron motivar el establecimiento en el reino nazarí de Granada de una producción cerámica de lujo, como la azul y dorada, aunque ello merecería abrir un nuevo debate dentro de los estudios ceramológicos granadinos poco apropiado en esta ocasión. No obstante podemos indicar que las referencias al comercio de cerámica entre los territorios nazarí y el magrebí confirman que la producción cerámica a que los documentos hacen referencia, seguramente la «loza azul y dorada», era reconocida fuera de las fronteras nazaríes como exclusiva de este territorio. Esta circunstancia supone un cambio sustancial respecto a lo que parece ser la norma hasta la instauración del reino granadino. En efecto, hasta bien entrado el siglo XIII, las producciones cerámicas, ya fueran de lujo como de uso común, mantenían unas características similares a uno y otro lado del Estrecho. Estas anotaciones textuales delatan sin embargo la existencia ya a mediados del siglo XIV de una producción cerámica diferenciada en el reino nazarí susceptible de ser usada como objeto de comercio. Llegados a este punto cabría preguntarse por las causas que motivaron su constitución.

42 Archivio di Stato di Genova, Sala 14, 1552, fols. 92 v-93 r., y 1553, fols. 7 r., 57 r.

43 A.S.P., A.D., Filza 1171, docs. 89 y 107.

44 Archivo de la Corona de Aragón, Generalitat, 186, fol. 86 r.

45 Manuel SÁNCHEZ MARTÍNEZ: «Comercio nazarí y piratería catalano-aragonesa (1344-1345)», en Mercedes GARCÍA ARENAL y Ma Jesús VIGUERA (ed.): Relaciones de la Península Ibérica con el Magreb. Siglos XIII-XVI. Actas del coloquio celebrado en Madrid en diciembre de 1987. Madrid, 1988, pp. 41-86, espec. p. 58.

46 Gomes EANES DE ZURARA: Crónica do Conde Dom Pedro de Menezes. Ed. facsímil José Adriano FREITAS CARVALHO. Oporto, 1988, vol. I, cap. XLII y vol. II, cap. XVI. 
Otra cuestión de no menos importancia es la que plantea el seguro concertado en Génova en 1393 y confiado al notario Andreolo Caito ${ }^{47}$. Antonio Cattaneo, genovés, asegura las mercancías de Nicolò de Mari, de Monelia, por un valor de 62 libras genovesas y 10 sueldos. Entre éstas, cargadas en el mismo puerto de Génova y destinadas a Pera, se cuenta una cantidad indeterminada de lo que denominan «vasorum de Malica». Aunque no se hace referencia explícita al material en que fueron realizados estos vasorum, todo parece indicar que la mercancía asegurada era cerámica, en especial si tenemos en cuenta la aclaración realizada un poco después respecto a que el seguro «...non teneat de rompimento vasorum...». La primera impresión de que estamos ante un tráfico de redistribución de más amplio alcance a partir de la base genovesa, puede resultar precipitada. De hecho, además de faltarnos aún ciertos datos que nos lo pudieran confirmar, hemos de tener en cuenta algunas cuestiones de carácter terminológico, en especial la conocida costumbre imperante en estos momentos de utilizar la denominación «de Malica» para designar la cerámica que empleaba en su decoración el dorado ${ }^{48}$. Práctica que se ha documentado ampliamente entre la documentación comercial valenciana, pero que tampoco parece ser exclusiva de los centros comerciales italianos ${ }^{49}$, y que puede ser indicativa de la prevalencia de las técnicas hispanas en la elaboración cerámica.

El estado de la investigación en la actualidad nos impulsa a inclinarnos por esta opción, aunque no debemos descartar la posibilidad de que se trate en realidad de cerámica nazarí incluida en las grandes líneas del tráfico internacional.

\section{La cerámicas del área valenciana}

Entramos de lleno, por tanto, en la producción valenciana. En primer lugar cabe aclarar que no siempre hablamos de producción valenciana de manera estricta. Aunque dentro de su órbita de influencia y sobre todo gestionadas desde la hacienda valenciana, en concreto directamente por su representante Luca del Sera, sabemos que, al menos en dos ocasiones, las adquisiciones de cerámica se realizan en Mallorca. Por lo demás es algo que no debe resultarnos extraño, si tenemos en cuenta que algunas cerámicas llegadas a Italia a lo largo del siglo X para ser utilizadas como decoración en las iglesias pisanas proceden de esta isla $^{50}$. La primera compra que conocemos, realizada en 1394, fue sacada a la luz por F. Melis al presentar el extracto de cuenta de la operación de compra y envío de 2 «cofa-

47 A.S.G., Notai Antichi, 312, Andreolo Caito (1393), fol. 202 r-v.

48 Pedro LÓPEZ ELUM: Los orígenes de la cerámica..., pp. 31-33; Guillermo J. DE OSMA: Los maestros alfareros..., pp. 5-9.

49 El Foral de portazgo de Lisboa, anterior a 1377, deja bien clara la generalización de esta tendencia: «Jtem de louça de Malega e de Valleça e de louça outra de barro que aqui fazem e que leuarem pera fora do thermo per mar ou per terra asy uezinhos como os que ni som vezjnhos pagam: dezima». Arquivo Nacional Torre do Tombo, Forais antigos, $\mathrm{m}^{\circ} 2, \mathrm{n}^{\circ} 3$. Edit en João Martins da SILVA MARQUES: Descobrimentos portugueses. Documentos para a sua História. Suplemento ao Volume I (1057-1460). Lisboa, 1988. pp. 51-60, espec. p. 53.

50 Graziella BERTI, Guillermo ROSSELLÓ BORDOY, Ezio TONGIORGI: «Alcuni bacini ceramici di Pisa e la corrispondente produzione di Maiorca nel secolo XI». Archeologia Medievale, XIII (1986), pp. 97-115. 
nes» ${ }^{51}$ de cerámica y otras 18 piezas sueltas ${ }^{52}$. La segunda es de 1397 y nos la descubre un cargamento de nave ${ }^{53}$, bastante más conciso que el detallado extracto, pero que en todo caso alcanza a aclarar la carga de 12 tinajas $^{54}$ de cerámica con destino a Pisa.

En los otros casos sí se habla concretamente de Valencia e incluso en alguna ocasión se especifica aún más la procedencia de Manises, hasta donde los agentes se han trasladado exclusivamente para realizar el encargo ${ }^{55}$. En efecto, ya los documentos valencianos hacen mención expresa a Manises y Paterna como lugares especializados en producción alfarera, en concreto la que presentaba una ornamentación destacada ${ }^{56}$. Pero han sido las excavaciones arqueológicas realizadas en estas dos localidades cercanas a Valencia las que han documentado de manera más explícita los centros donde se producían estas piezas, tanto en Manises ${ }^{57}$ como en Paterna ${ }^{58}$. Gracias a estas intervenciones conocemos la organización espacial interior de estos talleres, la evolución que experimentaron a lo largo del tiempo, las técnicas que emplearon para la elaboración de la cerámica y, sobre todo, lo numerosos que eran, al menos en los últimos siglos de la Edad Media. En nuestros documentos sólo se hace referencia a Manises ${ }^{59}$, e incluso se señala la necesidad de desplazarse desde la ciudad de Valencia, donde residía el agente comercial, hasta esta localidad. Este hecho parece señalar el alto nivel de especialización que alcanzaron como centros alfareros, apenas separados entre sí por el cauce del río Turia, en relación con el resto del territorio valenciano, incluida la propia ciudad.

Los documentos que hemos manejado ofrecen algunos datos más acerca de la organización del trabajo en estos talleres. Como ya se ha señalado en otras ocasiones, éste quedó esencialmente en manos de artesanos musulmanes ${ }^{60}$. No debemos olvidar en ningún caso que precisamente por la presencia de elementos decorativos de clara raigambre islámica resultaba muy atractiva y animaban la demanda de estas piezas. Los albarelos que se citan en el extracto de cuenta de 1394 (doc. 2) han sido comprados a un tal Ametto moro. Las

51 Coffa: «...corbello intessuto di vimini fatto a campana...entro cui si portano pietre, mattoni, ed anche zavorra, biscotto ecc. Per le navi». Información recogida en G. B. PELLEGRINI: «Contributo allo studio dell'influsso linguistico arabo in Liguria». Miscellanea Storica Ligure, II, pp. 11-95, espec. p. 36.

52 Federigo MELIS: Documenti per la Storia economica dei secoli XIII-XVI. Florencia, 1972, p. 252, doc. 60 .

53 A.S.P., A.D., Filza 1171/fasc. III, fol. 7 (1397/7/III).

54 Así hemos interpretado el término "giara" que aparece en la documentación, siguiendo con ello el criterio de Miguel Gual Camarena, aunque no lo aplica al transporte de esta mercancía. Miguel GUAL CAMARENA (ed.): El primer manual hispánico de mercadería (siglo XIV). Barcelona, 1981, p. 272.

55 A.S.P., A.D., Filza 547, Valencia-Pisa, doc. 600359 (1394/18/VII).

56 Citaremos por ser el más reciente el trabajo de Pedro LÓPEZ ELUM: Los orígenes de la cerámica...

57 Jaime COLL CONESA, Joaquín PÉREZ CAMPS: «Aspectos de la técnica de fabricación en la cerámica de Manises (siglos XIV-XVI)». Actas del IV Congreso de Arqueología Medieval Española. Alicante, 1993, t. III, pp. $879-889$.

58 Mercedes MESQUIDA GARCÍA, J. E. LÓPEZ PERIS, S. PRADES, R. SMOLKA: Las ollerías de Paterna. Tecnología y producción. Vol. I. Siglos XII y XIII. Paterna, 2001; Mercedes MESQUIDA GARCÍA: «Las alfarería, de Paterna en la Edad Media y Renacimiento», en IDEM (dir.): Cerámica de Paterna..., pp. 16-34.

59 A.S.P., A.D., Filza 547, Valencia-Pisa, doc. 600359 (1394/18/VII). Documento 2 del apéndice Documental.

60 Ésta parece ser una constante siempre que se han analizado documentos referentes a la producción cerámica valenciana bajomedieval. Pedro LÓPEZ ELUM: Los orígenes de la cerámica..., pp. 37-38 y pp. 73-74. 
continuas dilaciones del «moro» que realiza otro encargo en 1407 son objeto de varias referencias para excusar un retraso de hasta seis meses ${ }^{61}$. Hasta tal punto llega el descontento de los agentes encargados de gestionar la operación, que piden se les vuelvan a enviar los modelos de los diseños que han de ser reproducidos para entregarlos a otro artesano («...De l'opera di terra del Grasso non sapià che dirvi. Fa più di 3 settimane che il moro le fa. Ci disse che sanza falo la ci darebe e aci menato per novele... mandateci l'arme e faremole fare a un'altro moro e dite che opera vole...» $)^{62}$. No es desde luego la única ocasión en que se atribuyen retrasos a los artesanos encargados de las labores. Ya antes, en 1392, Uberto di Carlo degli Strozzi achacó un envío fuera de tiempo a la tardía recepción por parte del «moro» ${ }^{63}$. Todo ello nos podría indicar las dificultades a las que debían hacer frente los artesanos de Manises y Paterna para dar salida a los diversos encargos y, por consiguiente, el nivel productivo alcanzado por los talleres alfareros.

En todo caso las continuas quejas y notificaciones acerca de la marcha de los encargos constituyen valiosas informaciones. Nos permiten asegurar que los mercaderes italianos recurrieron directamente a los centros de producción, tratando personalmente con los artesanos, a los que se acude para satisfacer sus peticiones. Al menos no dan constancia de la existencia de intermediarios entre los alfareros y los comerciantes, como debió ser lo habitual con otros productos de mayor salida comercial, donde las redes de suministro y adquisición de las mercancías alcanzaban una complejidad y articulación acorde con el nivel de los intereses implicados y el desarrollo de estrategias de aprovisionamiento puestas en marcha ${ }^{64}$. La documentación que analizamos, sin embargo, no es muy explícita acerca del modo en que se efectuaban las comisiones. Sabemos, no obstante, que en algunos casos éstas eran muy precisas. Recordemos que la cerámica comprada en los centros valencianos presentaba grandes recursos decorativos, entre los que se incluían, a partir de una determinada época, los motivos heráldicos. Era relativamente frecuente que algunas piezas incluidas en los encargos se realizaran ad hoc, para lo cual el artesano debía seguir un modelo aportado por el mercader. La partida de cerámica de un tal Grasso que genera tanta controversia responde a este tipo de encargo. A lo largo de las varias cartas que tratan el asunto, aunque se señala que se trata de un grupo de albarelos o botes, por lo que podemos suponer que quien los encargó podría ser boticario o especiero, no se especifican las características morfológicas precisas del conjunto. No obstante queda fuera de duda que se trata de un pedido exclusivo que debe acogerse a un modelo decorativo determinado. En este caso, el hecho de que el modelo del diseño que se ha de reproducir esté en poder del artesano les impide desviar el encargo a otro más diligente («...Il moro fa l'opera di tera del Grasso ci mena per novele e no ne posiamo altro. Egli è stato malato da due mesi in qua. Pur che ci tornase l'armie lo faré fare ad altri e pur dicie che la fara

61 A.S.P., A.D., Filza 924, Valencia-Barcelona, docs. 516846 (1407/16/IX/), 516857 (1407/22/X/) y 516863 $(1407 / 12 / \mathrm{XI} /)$.

62 A.S.P., A.D., Filza 924, Valencia-Barcelona, doc. 516857 (1407/22/X).

63 A.S.P., A.D., Filza 795, Valencia-Génova, doc. 112798 (1392/3/V).

64 Caso, por ejemplo, de los frutos secos y el azúcar en el reino de Granada. Adela FÁBREGAS GARCÍA: «Vias de acceso del azúcar del reino de Granada al mercado europeo: La Sociedad de los Frutos (Siglos XIV-XV)». Actas del Seminario Internacional História do Açúcar. Rotas e mercados. Funcal (Portugal). Abril de 2002. 
e no la recha...» ${ }^{65}$ ), de manera que solicitan una nueva muestra en varias ocasiones a los intermediarios barceloneses para de este modo poder poner remedio a la situación ${ }^{66}$.

Junto a estos pedidos más específicos o personalizados encontramos partidas más abiertas de grupos cerámicos. Aparte, claro, de las muchas menciones en que sólo se utiliza el término genérico de «opera di terra», a ellas se alude cuando se habla de cerámicas contenidas en «giare», o los menos habituales en «chofano» o «corietto», en sus acepciones más amplias, como contenedor es de productos, sin aclarar las características de estas remesas.

En nuestra opinión es muy probable que en estos casos se tratara de lotes de cerámica compuestos por diversos tipos de piezas con las que se tenía cierta seguridad de que, una vez puestas a la venta en Italia, serían adquiridas sin grandes dificultades. De hecho, tal y como hemos podido constatar, es probable que ciertos mercados italianos fueran receptivos en lo que respecta a la cerámica valenciana. En efecto, en el área occidental de la Liguria, zona que hemos podido estudiar con mayor detenimiento, las cerámicas valencianas circulaban con cierta fluidez, lo que indicaría que estos materiales llegaban a sus mercados con frecuencia, satisfaciendo la alta demanda existente. Un mercurial referido a Savona indica los precios de las piezas valencianas puestas a la venta en este mercado. La mera presencia de estos artículos en el mercurial nos podría indicar, entre otras cosas, que el mercado de Savona era relativamente activo en lo que a este tipo de materiales cerámicos respecta ${ }^{67}$. De este modo podría señalarse que era de este lugar desde donde se distribuía gran parte de la cerámica que después se ha podido hallar en los contextos arqueológicos bajomedievales de la Liguria de Poniente. Sería en mercados de este tipo, donde la presencia de cerámica valenciana no sólo no era desconocida sino que podría incluso afirmarse que aparecía con cierta frecuencia, donde encontraran salida estos lotes de piezas de rastro apenas perceptible en los documentos.

En otras ocasiones se concretaba algo más acerca de las piezas que componían el encargo. En estos casos, probablemente, podría tratarse de pedidos realizados ex profeso por el futuro comprador. Lógicamente son estos últimos los que nos ofrecen más datos concretos sobre las piezas demandadas. Entre los grupos de cerámica a los que hacen referencia se enuncian los siguientes términos: piatelli $^{68}$, scodelle ${ }^{69}$, scodellini $^{70}$, vaselle ${ }^{71}$, alberelli ${ }^{72}$, bacini ${ }^{73}$, piati coperchiati o coperti ${ }^{74}$, taglieri, taglini

65 A.S.P., A.D., Filza 924, Valencia-Barcelona, doc. 516846 (1407/16/IX).

66 Ibidem y doc. 516863 (1407/24/XI).

67 Las relaciones del puerto savonés con productos españoles pareció ser relativamente estrecha, tal y como muestran diversos estudios. A. NICOLINI: «Viaggi e commercio nella Savona medievale». Rivista IngaunaIntemelia, XLII-XLIII (1987-1988), pp. 97-112.

68 A.S.P., A.D., Filza 547, Valencia-Pisa, doc. 424811 (1383/11/V) y Filza 1171, doc. 22 (s.f.).

69 A.S.P., A.D., Filza 547, Valencia-Pisa, doc. 424811 (1383/11/V), Filza 1171/II-1, doc. 90 (s.f.), Filza 924, Valencia-Barcelona, docs. 516814 (1407/2/VI), 516877 (1407/3/I), 516221, 516246, 516257, 516263, 516269 (1407/6-XII), y Filza 1171, doc. 22 (s.f.).

70 A.S.P., A.D., Filza 924, Valencia-Barcelona, docs. 516821, 576369 (1407/2/VI).

71 A.S.P., A.D., Filza 1171/ 107 (1/IX/s.a).

72 A.S.P., A.D., Filza 547, Valencia-Pisa, docs. 600336 (1394/18/II), 600359 (1394/18/VII), 600362, (1394/21/VII).

73 Ibidem, docs. 600366 (1394/24/VIII), 600367 (1394/7/IX). Federigo MELIS: Documenti...

74 Idem Ibidem. 
o tagliadori $^{75}$, $_{\text {radaleti }}{ }^{76}$ y salseroni $^{77}$. Se trata de una relación amplia, en la que parecen predominar las piezas destinadas al servicio de mesa, y en especial las que eran abiertas, algo que en los contextos arqueológicos conocidos vuelve a constatarse. En ningún caso se nos ofrecen más detalles acerca de las características o elementos morfológicos que estas piezas poseían.

Comentario similar debemos hacer respecto a los detalles que sobre la decoración pudieran ofrecer estos documentos. En ninguna ocasión se aclara si se trata de cerámica decorada o no, aunque sabemos que se comercia con ambas variedades, bien especificadas en el mercurial de Savona, donde se aclara que el precio de scodelle, salseroni, taglini y piatelli sin decorar es de 1 libra y 8 sueldos, y decorados, dorados para ser más exactos, de 2 libras y 2 sueldos $^{78}$. La diferencia de precio entre unas y otras es casi del doble. Dentro de esta variedad más rica hemos de incluir los «potes pintats» que viajan a Barcelona en 1404, posiblemente desde Valencia, aunque no se puede excluir su procedencia nazarí, en la nave del genovés Bartolomé Pinello ${ }^{79}$.

No resulta excesivamente complicado reconocer las piezas detalladas en nuestra documentación y relacionarlas con los tipos morfológicos que la metodología arqueológica ha venido aportando. Algunos trabajos nos parecen esenciales a este respecto. Resulta particularmente útil el reciente trabajo de M. Barceló Crespí y G. Rosselló Bordoy, ya que realiza una puesta al día de los términos expresados en documentos mallorquines, catalanes y valencianos, de donde proceden la mayor parte de las referencias estudiadas, así como las piezas halladas en el transcurso de las excavaciones arqueológicas que parecen guardar relación con ellas. En el ámbito italiano nos han resultado especialmente útiles los trabajos de M. Spallanzani y C. Renzi Rizzo, el primero porque en él también se ha usado documentación del Archivo Datini de Prato, mientras que C. Renzi Rizzo afronta la realización de un vocabulario de las piezas usadas en Toscana entre los siglos VIII al XVIII, área y período en que queda comprendido nuestro estudio ${ }^{80}$.

La voz piattelli parece corresponder a un recipiente de mesa de forma circular con un cuerpo poco profundo, ala más o menos acentuada y fondo amplio y plano ${ }^{81}$. Identificar el perfil que debía presentar esta pieza no parece ofrecer grandes dificultades, aunque precisar las dimensiones que poseía sí resulta más complicado. Todo parece indicar que debieron servir para el uso individual en la mesa, de modo que sus proporciones debían encontrarse entre las destinadas al servicio colectivo de los alimentos y aquellas piezas individuales adscritas a otras tareas (salseras, escudillas, etc...). Por convención se suele

75 A.S.P., A.D., Filza 924, Valencia-Barcelona, docs. 516814 (1407/2/VI), 576369 (1407/2/XII) y Filza 1171, doc. 22 (s.f.).

76 Federigo MELIS: Documenti...

77 A.S.P., A.D., Filza 1171, doc. 22 ( s.f.).

78 A.S.P., A.D., Filza 1171, doc. 22, (s.f).

79 A.C.A., G. 186/1, fol. 86 r., (1404/XI).

80 María BARCELÓ CRESPÍ, Guillem ROSSELlÓ BORDOY: Terrissa. Dades documentals...; Marco SPALLANZANI: Un invio di maioliche ispano-moresche..., y Catia RENZI RIZZO: «"Nomina Vasorum”...», pp. 285-320.

81 Catia RENZI RIZZO: «"Nomina Vasorum”...», p. 312, s.v. Piattello. En el área pisana esta denominación parece extenderse desde finales del siglo XIV, y en principio también se refería a platos de estaño. 
indicar que las piezas con un diámetro superior a $25 \mathrm{~cm}$ dejan de ser un plato para comer para ser utilizadas como soporte de servicio ${ }^{82}$. En cualquier caso, la experiencia arqueológica nos indica con claridad la existencia de una amplia diversidad de tipos de plato (con fondo plano, cóncavo, ala más o menos amplia), aunque todos mantengan el perfil general señalado. Estas piezas de servicio individual no aparecen en las vajillas cerámicas medievales españolas antes de finales del siglo XIII. Sólo a mediados del siglo XIV su uso, tal y como señalamos, comienza a extenderse tanto entre los materiales arqueológicos como en las anotaciones escritas.

Los términos scodelle y scodellini, su derivado, parecen referirse a otro tipo de piezas. Debía tratarse de recipientes redondos y cóncavos, dotados o no de ala y de anchura variable ${ }^{83}$. La diversidad es notable, tal y como ponen de manifiesto tanto los datos arqueológicos como la documentación escrita ${ }^{84}$. En este caso las variantes hacen referencia al tamaño (grandes, pequeñas, etc...), a su procedencia, a detalles de carácter formal o decorativo (en algunos casos se señala la presencia de ala u orejas, o la existencia o no de repié), o bien a su funcionalidad ${ }^{85}$. En este sentido, queremos destacar la mención que aparece en un documento de finales del XIV (1394-1395). Se trata de un libro de contabilidad adscrito a la misma compañía Datini y relativo a la actividad de su hacienda catalana, concretamente a las sedes mallorquina y valenciana. El 18 de diciembre de 1394 se registra «...una giarra di schodelle da insalata con maniglie, furon 45, a s. 23 la dozina...» ${ }^{86}$. Algunos años más tarde, a mediados del siglo XIV, en un precioso documento publicado por G. de Osma, en el que se relacionaban algunas cerámicas que demandaba la reina Dña. María de Aragón, se vuelve a hacer referencia detallada de este tipo de piezas, junto a otras. De este modo se decía «Item: scudellas; Item: scudelles primes pera beure brous», y un poco más abajo «...Item: scudelletes et obra menuda; Item: scudelles pera fer brous sechs...» ${ }^{87}$. En ocasiones se ha considerado que esta precisión textual debe corresponderse con las diversas variantes formales que la serie escudilla ha ofrecido a los arqueólogos, en especial por lo que a dimensiones y grosores se refiere ${ }^{88}$. Ciñéndonos a esta hipótesis, parece claro que el término «scudella» y sus derivados y variantes designan una pieza cerámica muy extendida y diversificada, seguramente debido a las diferentes funciones que pudiera desempeñar dentro de la vajilla bajomedieval.

Un término poco usado en nuestra documentación es el de vaselle. La única ocasión en que lo encontramos aparece asociado, curiosamente, al término casse, al hacer referencia al contenedor que lo transportaba, en lugar de la habitual giara $^{89}$. Parece tratarse de un

82 Maria BARCELÓ CRESPÍ, Guillem ROSSELLÓ BORDOY: Terrissa. Dades documentals..., p. 151. Respecto a este término se ha dicho «...la costante presenza della voce «piatello», che rimanda ad un piatto grande, mentre i pezzi dalle dimensioni modeste venivano detti «piattelli piccoli o piattelletti»» en Marco SPALLANZANI: Ceramiche orientali..., p. 41, nota 29.

83 Catia RENZI RIZZO: «"Nomina Vasorum”...», p. 313, s. v. Scutella y Schudellinus.

84 Maria BARCELÓ CRESPÍ, Guillem ROSSELLÓ BORDOY: Terrissa. Dades documentals..., p. 159.

85 Véase el estudio de Marco SPALLANZANI: Un invio di maioliche ispano-moresche..., p. 530 («scodelle c'l'orlo, scodelle piane, scodelle grandi...», entre otras variantes).

86 Bruno DINI: Una pratica di mercatura in formazione (1394-1395). Florencia, 1980, p. 121.

87 Guillermo J. OSMA Y SCULL: La loza dorada..., p. 6.

88 Maria BARCELÓ CRESPÍ, Guillem ROSSELLÓ BORDOY: Terrissa. Dades documentals..., p. 149.

89 A.S.P., A.D., Filza 1171, doc. 107 (1/IX/s.a). 
término de significado un tanto genérico que designa, sin mayor precisión, los productos salidos de los talleres cerámicos. Podría asociarse en Toscana, aunque la documentación no es muy clara, a piezas esmaltadas o cerradas, usadas como medidas de capacidad de líquidos $^{90}$. Sería, por último, la traducción del término latino vasorum, usado contemporáneamente en Génova y que hemos constatado en algunos documentos notariales.

Los alberelli sí son más claramente reconocibles. Se trataba de una de las piezas que presentaba una mayor salida, ya sea por sus citas en documentos de la época, o por las constataciones materiales realizados fuera de la Península Ibérica. Es una pieza cerrada, cilíndrica, con un cierto estrechamiento central. Su etimología presenta ciertos problemas de interpretación, aunque no su función, que parece ser precisa: vaso para especies ${ }^{91} \mathrm{o}$ algún otro tipo de sustancia preciada. Una anotación realizada por la compañía Datini en Pisa lo señala con claridad: "Chompera in Valenza per noi di due botti e due giarre di alberelli da speziali» ${ }^{92}$. De hecho en los inventarios mallorquines, cuando se especifica el contenido, suelen aparecer materias (gengibre, azúcar, etc.... $)^{93}$. El nombre utilizado en Baleares es diferente al documentado en Italia; aparece bajo la voz pot, en un buen número de ocasiones asociado con las labores propias de la farmacia.

El término bacini es bien conocido, ya que con él se designan las cerámicas que, incrustadas en los muros, decoraban los campanarios y fachadas de las iglesias italianas del área centro-septentrional. Este término comenzó a ser reconocido como voz para designar estas piezas de finalidad eminentemente decorativa, a mediados del siglo XVIII, aunque fue a principios del XX cuando se tomó conciencia del interés que éstas podían suscitar, y se produjeron las primeras tomas de posición en favor de su estudio y conservación ${ }^{94}$. El término, como puede deducirse de nuestra documentación, se usaba con frecuencia para referirse a cerámicas de gran porte, como lo son efectivamente las utilizadas en la decoración muraria, si bien su significado no abarcaba un campo morfológico tan amplio como el que aparece recogido actualmente bajo esta denominación. Se trataba de un plato de grandes dimensiones con cavidad central profunda, destinado a contener una buena cantidad de líquido. Por estas características era utilizado en ocasiones para la higiene personal ${ }^{95}$.

Otra de las piezas documentadas son los piati coperchiati o coperti. El término piatti comparte la raíz de la voz piattelli, a la que hemos dedicado algunas líneas más arriba. La forma también debió ser común en una y otra pieza, pero las dimensiones y, por lo tanto,

90 Catia RENZI RIZZO: «"Nomina Vasorum”...», pp. 317-318, s.v. Vagelli.

91 Catia RENZI RIZZO: «"Nomina Vasorum”...», pp. 299-300, s.v. Albarellus.

92 La anotación procede de un registro en el «Libro rosso di mercanzie B» (1394-1395), estudiado por E. GUIDI: La vitalità della piazza di Pisa alla fine del XIV secolo attraverso la contabilità del fondaco pisano Datini (Memoria de Licenciatura 1953-1954) y mencionado por Liana TONGIORGI: «Pisa nella storia della ceramica». Faenza, L (1964), nº I-III, pp. 3-24, espec. pp. 7-8, nota 30.

93 Maria BARCELÓ CRESPÍ, Guillem ROSSELLÓ BORDOY: Terrissa. Dades documentals..., pp. 79-80 y 172 .

94 Véase Graziella BERTI, Liana TONGIORGI: I bacini ceramici medievali..., p. 9 y Gaetano BALLARDINI: «Per un "Corpus" dei bacini di ceramica dei nostri antichi monumenti». Faenza, XXVI (1938), pp. 3-16.

95 Catia RENZI RIZZO: «"Nomina Vasorum”...», p. 301, s.v. Bacilis. Etimológicamente esta voz parece proceder de Bacino. Véanse también las líneas dedicadas a la voz bacina, documentada a finales de la Edad Media y a principios del siglo XVI en Mallorca. Maria BARCELÓ CRESPÍ, Guillem ROSSELLÓ BORDOY: Terrissa. Dades documentals..., pp. 35-36. 
la función, pudieron variar entre ambas. Los piatti parecen presentar un diámetro mayor, destinándose probablemente al consumo en común de determinados alimentos, aunque resulta complicado delimitar las diferencias semánticas entre estos dos términos. Incluso entre los mismos piatti existen diferencias de diámetros. Un documento pisano algo más tardío, de 1562, deja claro los diferentes tipos de platos en relación con sus dimensiones y las funciones que pudieron cumplir: «...e tre piatti grandi per fare l'insalata a battuti e 8 piatti mezani e sei picholi..» ${ }^{96}$. Es probable que su capacidad permitiera también su uso para la conservación de determinados alimentos, lo que pudo llevar aparejado que vinieran acompañados por una pieza complementaria: la tapadera o coperchio $^{97}$. Este extremo explicaría la asociación entre ambas formas que se refleja en nuestros documentos. En cualquier caso, no era infrecuente vender algunas piezas cerámicas, ya sea por su valor decorativo como por su función específica, con la tapadera que las acompañaba ${ }^{98}$.

Los términos taglieri, taglini o tagliadori que aparecen en nuestros documentos parecen proceder de la raíz común talire. Es un sustantivo derivado del latín tardío y transmitido a través del francés antiguo tailloir ${ }^{99}$, aunque en algunos inventarios domésticos provenzales de finales de la Edad Media aparecen como tailladorsi, talhadors o tallerios ${ }^{100}$. En los territorios de la Corona de Aragón corresponde al término tallador ${ }^{101}$. En todo caso, la función que desempeñaba y la forma que presentaba se conocen con certeza. Se trata de una pieza de gran diámetro y escasa profundidad, apropiada para el servicio y presentación de alimentos que debían ser trinchados en la mesa ${ }^{102}$.

Sólo en una ocasión aparecen mencionados los gradaleti. No parecen ser, por lo que conocemos hasta el momento, unas piezas demasiado extendidas, incluso entre el material italiano de la misma época. Por lo demás, la forma que presentaban estos gradaleti aún no ha podido ser confirmada completamente. Algunos documentos pisanos los citan refiriéndose a piezas de pequeño tamaño destinadas al servicio de mesa, como sinónimo del término italiano catino. Incluso se ha llegado a insinuar que pudieran destinarse a contener especias $^{103}$. Algunos de estos vasos pisanos pudieron proceder incluso de Ma-

96 Procedente de la Università dei Cappellani del Suono di Pisa, Entrate e Uscite, (1558-1574). Catia RENZI RIZZO: «"Nomina Vasorum”...», p. 312.

97 Catia RENZI RIZZO: «"Nomina Vasorum”...», p. 306, s.v. Coperchius.

98 Pongamos como ejemplo Marco SPALLANZANI: Ceramiche orientali..., pp. 176-177, 188-191 (documentación medicea) o Catia RENZI RIZZO: «"Nomina Vasorum”...», p. 313, referido a una saleria (salero) en un documento de 1329.

99 Catia RENZI RIZZO: «"Nomina Vasorum”...», p. 315, tomado de M. CORTELAZZO, P. ZOLLI: Dizionario Etimologico della Lingua Italiana. 5 vols. Bolonia, 1979-1988.

100 AA.VV.: «Materiaux pour l'étude de la vie domestique et la culture materielle en Provence aux derniers siècles du Moyen Âge». Razo. Cahiers du Centre d'Études Médiévales de Nice. Niza-Sophia Antipolis, 1993, pp. 48 (doc. 1-39), 86 (doc. 11-24) y 99 (doc. 16-56).

101 Miguel GUAL CAMARENA: Vocabulario del Comercio Medieval. Colección de aranceles aduaneros de la Corona de Aragón (siglos XIII-XIV). Barcelona, 1976, p. 453, s.v. Tallador.

102 Maria BARCELÓ CRESPÍ, Guillem ROSSELLÓ BORDOY: Terrissa. Dades documentals..., pp. 88-89 y 151.

103 Liana TONGIORGI: Pisa nella storia..., p. 11, nota 53, siguiendo a DU CANGE: Glossarium mediae et infimae latinitatis conditum a Carolo Du Fresne domino Du Cange, 9 vols. Niort, 1883-1887, vol. IV, p. 91, s.v. Gradalus. 
llorca $^{104}$. Por el momento no hemos encontrado un término usado en la Península o en las Baleares que pudiera corresponder con éste.

Por ultimo nos referiremos a los salseroni. Éste resulta ser el caso inverso al anteriormente estudiado. Lo encontramos profusamente entre los inventarios mallorquines bajo el nombre de salsera, refiriéndose a un contenedor destinado a guardar o servir una salsa o producto semejante, aunque no pueden deducirse de estas informaciones unos rasgos morfológicos concretos ${ }^{105}$. Sin embargo no hemos hallado en los estudios sobre cerámica italiana contemporánea referencia documental alguna, aparte de la aportada por nuestro documento, a un término que pueda corresponder con el de salseroni. Sí lo hallamos en los inventarios provenzales contemporáneos, aunque relativo a piezas realizadas con estaño ${ }^{106}$.

\section{Los contenedores utilizados para el transporte}

Tal y como muestran los documentos que estudiamos, las piezas cerámicas se venden en muchas ocasiones medidas en docenas ${ }^{107}$, y en la mayoría de los casos en conjuntos o lotes que suelen corresponder a los mismos contenedores que los transportaban «...di quelle mie opere di tera, cioe 4 giare sinya (signo) che vi mandai per la nave di Antonio Muzolo fino di 8 gienaio, delle quale mi scrivesti averne finito giare $31 / 2$ a s. 75 e tre mesi ,e l'altra meza giarra era rimaso perche la giarra era rotta. Ma diciesti finilla sanza giarra, che ogi mai penso pure debbe esere finita e i denari riscosi. E simile di quelle 3 $1 / 2$ gia(rre) vendute a tre mesi. E per molte lettere v'ò scritto mi ne avis(ate)... mai nulla n'ebbi. El percheècome per l'altre vi disse vi pregho o dette opere o le dette se denari non sono avuti faciate consenyare a quelli di Gualtieri Portinari e conpagni e elino ve ne farano una lettera di contenta...» ${ }^{108}$.

De los contenedores utilizados para el transporte de cerámica en el largo trayecto entre los centros donde fue producida y aquéllos donde fue comprada, la giara resulta la más citada ${ }^{109}$. Con esta voz italiana se conocía a la tinaja o alfabia en el área aragonesa, contenedor por excelencia en la Baja Edad Media. La forma que presentaba esta pieza variaba sustancialmente entre la fabricada en territorios islámicos y la elaborada en talleres cristianos bajomedievales. Podría señalarse como diferencia fundamental la presencia de un cuello desarrollado en la primera, al menos a partir del siglo XII, elemento morfológico que no parece ser habitual en la tinaja cristiana bajomedieval ${ }^{110}$.

104 Catia RENZI RIZZO: «"Nomina Vasorum”...», pp. 307-308, s.v. Gradalectus. En un documento de 1402 se dice «gradalettos sex de terra de Maiorica» (Spedali S. Chiara, no 52, c. 212 v.).

105 Maria BARCELÓ CRESPÍ, Guillem ROSSELLÓ BORDOY: Terrissa. Dades documentals..., pp. 84-85.

106 Bajo la voz Salseria o Salceria AA.VV.: Materiaux pour l'étude..., p. 56 (doc. 3-131), 60 (doc. 4-101), 72 (doc. 6-66) y 89 (doc. 12-16).

107 Recordamos aquí los comentarios de G. J. De Osma «Los precios en estas ventas, que son al por mayor, se expresan por gruesas y docenas... ». Guillermo J. DE OSMA: Los maestros alfareros..., p. 13.

108 A.S.P., A.D., Filza 795, Valencia-Génova, doc. 112793 (14/XI/1393).

109 Catia RENZI RIZZO: «"Nomina Vasorum”...», p. 307, s.v. Giarra con referencias documentales.

110 Para la primera pueden consultarse Guillermo ROSSELLÓ BORDOY: Ensayo de sistematización de la cerámica árabe de Mallorca. Palma de Mallorca, 1978, pp. 78-81; Rafael AZUAR RUIZ: Denia islámica. 
Tinajas islámicas han aparecido con cierta frecuencia en las ciudades costeras italianas. Estos hallazgos parecen concentrarse en determinadas áreas, como el Lazio septentrional ${ }^{111}$, o en algunas localidades toscanas tales como Pisa y Ripafratta, un castillo en el camino que une Pisa y Florencia a través del curso del río Arno ${ }^{112}$, además de en algunos puertos ligures o sardos ${ }^{113}$. Por lo general se trata de fragmentos estampillados, en algunos casos acabados con una cubierta vítrea verde. Hemos de destacar entre estas piezas el hallazgo de un reposadero de tinaja hallado en Finalborgo (Savona ${ }^{114}$. Éste se utiliza para separar la tinaja del pavimento, evitando la transferencia de temperatura del suelo a la tinaja. La presencia de esta pieza nos podría indicar que después de una fluida circulación de la tinaja como contenedor de otros bienes de comercio por los puertos ligures, llegaría a convertirse en sí misma en un objeto de venta, demandado conjuntamente con el reposadero y dispuesto por tanto para desempeñar otras funciones domésticas bien distintas de las usuales hasta entonces.

Tinajas o alfabias cristianas también se han encontrado en varias localidades italianas ${ }^{115}$, especialmente toscanas. Algunas de estas piezas, de morfología claramente relacionable con las piezas del área aragonesa ${ }^{116}$, presentan ciertas marcas, ya sean estampilladas como pintadas, que bien podrían asociarse a los signos usados para la identificación por parte del comerciante de la mercancía que había encargado. Son, además, signos que aparecen diseñados en los documentos comerciales italianos ${ }^{117}$. La función de recipiente de transporte de este tipo de tinajas de cerámica parece en este caso claro, aunque es muy probable que siguieran siendo utilizadas para la conservación de productos tales como agua, vino o aceite

Arqueología y poblamiento. Alicante, 1989, pp. 284-286, o Manuel RETUERCE VELASCO: La cerámica andalusí de la Meseta. Madrid, 1998, vol. I, pp. 354-359, entre otros estudios. Un análisis riguroso de la alfabia mallorquina bajomedieval, sobre la forma que presentaba, su capacidad y la función que desempeñó a partir de los datos aportados por el registro documental, lo encontramos en María BARCELÓ CRESPÍ, Guillem ROSSELLÓ BORDOY: Terrissa. Dades documentals..., pp. 26-33.

111 Romualdo LUZI: «Altre ceramiche dalla Torre di Vulci dallo scavo del 1988», en Albertina CORSINI (a cura di): Vulci. Ceramiche dal “butto" della Torre. Tarquinia, 1990, pp. 165-169 y Francesca ROMANA STASOLLA: «Primi rinvenimenti di ceramica comune da Cencelle», en Elisabetta DE MUNICIS (a cura di): La ceramica di Roma e del Lazio in età medievale e moderna. Atti del III Convegno di Studi. Roma, 1998, pp. 70-76, espec. p. 73, fig. 7.

112 Graziella BERTI, Liana TONGIORGI: «Frammenti di giare con decorazioni imprese a stampo trovati a Pisa». Faenza, LVIII, (1972), n 1, pp. 3-10 y A. CAVICCHI: «Ispano-moresca», en Fausto REDI (a cura di): Medievo vissuto. Primi dati sulla cultura materiale del castello di Ripafratta. I reperti dello scavo. Pisa, 1990, pp. 81-86.

113 Véase como ejemplo Tiziano MANNONI: La ceramica medievale..., pp. 21-22, tipo 6a, fig. 8.

114 Alessandra FRONDONI, Giovanni MURIALDO, Paolo PALAZZI, Marco PANIZZA, Loredana PARODI: «Gli scavi di Piazza Santa Caterina in Finalborgo (Savona): Primi dati sui reperti ceramici». XXXIII Convegno Internazionale della Ceramica. Savona, 2000, pp. 177-188, espec. pp. 180-181, fig. 9.

115 Un excelente estudio en Riccardo FRANCOVICH, Sauro GELICHI: La ceramica spagnola..., pp. 28-39, fig. 7 .

116 Véanse entre otros Jaume COLL CONESA: «Contenedores cerámicos medievales en las costas de Mallorca». IV Congreso de Arqueología Medieval Española. Alicante, 1993, vol. III, pp. 1069-1079 o Maria BARCELÓ CRESPÍ, Guillem ROSSELLÓ BORDOY: Terrissa. Dades documentals..., pp. 166-167.

117 Véase François AMIGUES, E. CRUSSELLES, Ricardo GONZÁLEZ VILLAESCUSA, Josep Vicent LERMA: «Los envases cerámicos de Paterna/Manises y el comercio bajomedieval». Actes du 5ème colloque sur la céramique médiévale. Rabat, 1995, pp. 346-361, espec. pp. 348-350. 
una vez llegaron a los puertos italianos, o bien desempeñaran otras labores subsidiarias tales como la construcción, aligerando el peso de las bóvedas ${ }^{118}$.

Por último respecto al vocablo vasi, se han documentado en Toscana dos significados para la época medieval. Uno bastante genérico, que podría ser sinónimo de la palabra pentolame, o aún como lavoro di terra, opera di tera o vasellame; otro, algo más preciso, parece referirse a una pieza cerrada dedicada a la medida de líquidos ${ }^{119}$. Podríamos asociar las piezas denominadas vasi en nuestra documentación a la última acepción señalada. Bajo la forma vaxell, la encontramos documentada en Mallorca. En este caso se trata también de un término genérico ${ }^{120}$.

\section{LA CERÁMICA ESPAÑOLA EN LAS REDES COMERCIALES BAJOMEDIEVALES ITALIANAS}

Con el presente trabajo hemos tratado de realizar, basándonos en algunas notas documentales, la evolución del comercio de la cerámica procedente de la Península Ibérica en Italia. Este flujo de materiales cerámicos entre ambos territorios comienza a documentarse ya en el siglo X, tanto en excavaciones arqueológicas como en algunas iglesias del área tirrénico septentrional donde eran utilizados como decoración arquitectónica.

La primera anotación de la que tenemos constancia es del siglo XII, aunque el caudal mayor de información documental procede de los últimos siglos medievales, período en el que arqueológicamente se documenta una importación relevante de este tipo de materiales. Esta introducción fue iniciada por la cerámica almohade y nazarí decorada en azul y dorado, aunque fue tempranamente retomada por la producción cerámica elaborada en las proximidades de la ciudad de Valencia durante los siglos XIV y XV. Uno de nuestros documentos se refiere concretamente a Manises, donde la elaboración cerámica de lujo en época medieval está claramente atestiguada por documentos valencianos y excavaciones arqueológicas realizadas en su casco urbano ${ }^{121}$.

Para mantener el nivel de demanda alcanzado por su predecesora malagueña, la cerámica elaborada en valencia debió asumir los caracteres decorativos y tecnológicos desarrollados en el territorio nazarí. Es por ello que la mayor parte del tejido artesanal estuvo ocupado por musulmanes o mudéjares. En el mismo documento donde se hace referencia a Manises, se señala a un tal Ameto como el artesano que debía elaborar el pedido. Y nuestro documento no es único, ya que esta cuestión aparece reflejada con mucha frecuencia en la documentación valenciana. Ante esta evidencia muchos autores han señalado la posibilidad de que estos artesanos llegaran a territorio valenciano desde el reino nazarí o, siguiendo los patronímicos de algunos artesanos, de Murcia, atraídos,

118 Joan BASSEGODA NONEL: La cerámica popular en la arquitectura gótica. Barcelona, 1983, o M ${ }^{\mathrm{a}}$ del Carmen RIU DE MARTÍN: «Las piezas de cerámica halladas en las bóvedas de las iglesias barcelonesas del siglo XIV». Acta Historica et Archeologica Mediaevalia, 13 (1992), pp. 175-424.

119 Catia RENZI RIZZO: «"Nomina Vasorum”...», p. 318, s.v. Vas.

120 Maria BARCELÓ CRESPÍ, Guillem ROSSELLÓ BORDOY: Terrissa. Dades documentals..., p. 92.

121 Jaime COLL CONESA, Josep PÉREZ CAMPS: «Aspectos de la técnica de fabricación en la cerámica de Manises (siglos XIV-XVI)», en IV Congreso de Arqueología Medieval Española. Alicante, 1993, vol. III, pp. 879-889. 
al parecer, por ciertas condiciones que podían favorecer la producción cerámica en las proximidades de Valencia.

Todos estos factores influyeron de manera decisiva en la creación de numerosos talleres alfareros en esta zona. Talleres de gran capacidad productiva, que orientaban en muchas ocasiones gran parte de sus productos hacia el comercio.

En cualquier caso, al referirnos a la cerámica como objeto de intercambio en las redes comerciales bajomedievales, hemos de señalar necesariamente que se trata a todas luces de un objeto de comercio secundario, muchas veces subsidiario, que aprovecha el soporte logístico levantado por los mercaderes italianos para garantizar el aprovisionamiento de los bienes que más les interesan y que animan la actividad mercantil en esta zona. Tanto los grandes movimientos que constituyen el cargamento de una nave, como las operaciones y envíos individuales de media o pequeña envergadura, secundan y confirman un carácter eminentemente ocasional y de menor relieve.

Otro de los aspectos mostrado por los documentos comerciales, es la forma de las piezas cerámicas. Los documentos que hemos manejado nos presentan una tipología amplia y diversificada, ya sea por el tamaño de las piezas (se hace referencia tanto a pequeñas escudillas como a grandes platos o talladores), como a las diferentes características morfológicas que podían presentar. Sin embargo, las funciones que desempeñaron no fueron muy variadas. Generalmente se trata de vajilla destinada al servicio de mesa y al consumo de alimentos. Sólo los albarelos presentan un destino algo distinto al de la mesa de las altas familias italianas. Estos vasos sirvieron para el almacenamiento de productos de cierta calidad, con una finalidad esencialmente medicinal o farmacéutica.

En cualquier caso su posición, ya sea en un contexto doméstico como en el establecimiento de un boticario, era destacada, destinada a ser contemplada y admirada, lo que determinó que presentaran un aparato decorativo desarrollado en el que destacaban motivos de diverso tipo: geométrico, vegetal, figurado, etc... En un primer momento de clara inspiración islámica (s. XIV), aunque con el transcurso del tiempo fueron sustituidos paulatinamente por motivos decorativos de carácter gótico. Entre estos últimos destacan los heráldicos, encargados de manera expresa por los clientes y trasladados por los agentes comerciales, por medio de diseños, a los artesanos, quieres estaban obligados a reproducirlos sobre las piezas cerámicas. Este procedimiento, ya supuesto por las numerosas piezas elaboradas en Valencia que portan escudos de familias italianas, queda puesto claramente de manifiesto en uno de nuestros documentos al hacer referencia a las «armas»; escudo familiar del cliente.

Los puertos de llegada de esta cerámica en Italia se distribuyen según nuestra documentación entre Toscana y Liguria. Pisa ${ }^{121}$ es un destino frecuentado con cierta asiduidad, aunque también aparece Livorno ${ }^{122}$ como destino toscano, ciertamente, en medida mucho más reducida. Queda clara en todo caso la función de centro redistribuidor que desempeña Pisa, no sólo en la Toscana, desde donde en ocasiones se dirige a Florencia ${ }^{123}$ o incluso a

122 Ibidem, docs. 600214 (1406/8/XII), 600230 (1401/28/V), 600328 (1393/26/XII), 600359 (1394/18/ VII), 600362 (1394/21/VII), 600366 (1394/24/VIII), 424701 (1400/10/XII), 424811 (1383/9/X); Filza 795, doc. 512611 ([393/31/X); Filza 1171/fasc. III, fol. 7 (1393/7/III).

123 A.S.P., A.D., Filza 547, Valencia-Pisa, docs. 424699 (1400/14/VII), 112784 (1392/16/VII). 
Génova ${ }^{124}$. También aparece como mercado de venta de las piezas ${ }^{125}$, aunque en todo caso la gestión de las mismas se realiza desde uno de los centros anteriores, concretamente desde Génova. Es el caso representado por las diversas operaciones tramitadas para la familia de los Strozzi, cuyas partidas llegan y se venden en los puertos y mercados toscanos, pero se controlan desde la hacienda genovesa, y es a ésta a la que la compañía de los Strozzi se dirige para conocer la marcha del negocio ${ }^{127}$.

En cuanto al área ligur, que también mantiene una tradición bastante sólida en la recepción de cerámicas peninsulares, son los puertos de Savona y Génova los polos de entrada de cerámica hispánica. Ya hemos comentado el rol organizador que asume Génova, o la hacienda genovesa de los Datini, en la redistribución cerámica española en la Península italiana. Se trata evidentemente de áreas comprendidas en su órbita de influencia, caso de los puertos toscanos de Pisa y Livorno. Recordemos por último el mercurial redactado en Savona, sin fecha, aunque sabemos que se incluye en el muy restringido arco temporal de vida de la compañía Datini, en donde aparecen tarifas de cerámica valenciana. Se ofrecen precios de venta en este mercado de cerámica dorada y sin dorar ${ }^{128}$. En otra ocasión, esta vez datada en febrero de 1400, se confirma la sensación de que éste resulta un buen mercado de recepción y venta de la cerámica valenciana. La declaración de que «vendeci anche alchune giare d'opera di tera ${ }^{129}$ de Valencia, revela el interés sobre un artículo lo suficientemente importante, desde luego, como para merecer su inclusión en un mercurial, observatorio privilegiado de las características de un mercado concreto.

Los materiales cerámicos hallados en excavaciones arqueológicas italianas no hacen más que confirmar los datos aportados por la documentación escrita y ampliar los lugares adonde llegaban estas cerámicas. En esencia se observa como a lo largo de los siglos XIV y XV, la circulación de materiales cerámicos se va haciendo más fluida, rebasando los estrechos límites de las ciudades comerciales italianas y alcanzando paulatinamente núcleos urbanos de menor entidad o asentamientos rurales relativamente alejados de las ciudades, como ciertos castillos feudales.

124 Ibidem, doc. $424698(1400 / 20 / \mathrm{V})$.

125 Ibidem ,docs. 600321 (1393/9/XI) y 600366 (1394/24/VIII).

126 AD, Filza 795, Valencia-Génova, doc. 112784 (1392/16/VII).

127 Ibidem, docs. 112804 y ss. y $112801(1392 / 22 / \mathrm{V})$.

128 A.S.P., A.D., Filza 1171, doc. 22 (s.f.).

129 A.S.P., A.D., Filza 1003, Savona-Valencia, doc. 423002 (1400/19-/II). 


\section{APÉNDICE DOCUMENTAL}

AD, filza 795, Valencia-Génova. F. Datini y Luca del Sera a F. Datini y Andrea di Bonanno. Doc. 512609. $\mathrm{A}^{130}$

Valencia, 31 de octubre de 1393.

Extracto de cuenta de cosas compradas para Andrea de Voltabio y Agostino Fredi, con 2 tinajas de cerámica y 6 piezas entre bacini y conche.

Al nome di Dio, a dì XXXI d'otobre 1393.

Ponete a chonto che dare ci dobiate conperamo per Andrea da Voltabio e Agostino ${ }^{131}$ Fredi co(me) apreso diciamo e manderenvi per lo primo passaggio [Signo].

Opera di tera giari grosse II e pezi VI tra bacini e conche per s. XXIIII grossi, monta per tuto

11. II s. XI barza'

Per sisa

Per caricare e hostallagio dell'oste di mare

11. (lac) s. I

Per tute lelde

11. (lac) s. I

Per I giara ${ }^{132}$ non costò nulla e non po(nete) nulla

11. (lac) s. III

Somma 1l. II s. XVI d. V barza'.

11. (lac)

E chosì ponete a nostro conto ${ }^{133}$ qui e la $1 / 2$ vi fate rendere And(rea) e l'altra $1 / 2$ ad Agostino e si ${ }^{134}$ le spexe vi facesi voi consto.

E più ponete dare ci dobiate per saca $\mathrm{X}$ d'agnini conperati per Firenze ${ }^{135}$ per voi, i quali sono a Panischola e per la prima nave costì o Pisa gli vi mandiamo [Signo]

Agnini saca X rove L, a s. XVII d. III rova, monta

11. 43 s. 2 d. 6

Per X sachi, filo e chucire

11. 2 s. 12

Per mandare sachi voti a luoghi e stivare

11. (lac) s. 10

Per senserie

11. (lac) s. 5 d. 6

E contaci Michel Francho avere spexo ${ }^{136}$ in soma

XXIIII del bocazee con I bestia

11. 1 s. (lac)

Per tute lelde

11. 1 s. 15 d. 6

Per caricare e hostallagio del'oste de Paniscola

11. (lac) s. 8 d. 6

Per nostro dritto

11. (lac) s. 15

130 Copia en 512610 (B)

131 En B: Aghostino.

132 En B: e coperchio.

133 En B:

134 En B: e così le altre.

135 En B: quelli di Firenze e voi per 1/2.

136 En B: avere spexo Michel Francho con I bestia nelglí agnini del bochazee. 
Soma costo e spese 1l. L s. VIIII, di che toca a voi per la $1 / 2 \quad$ 1l. XXV s. IIII d. VI bar. $\mathrm{E}$ così ponete a conto ${ }^{137}$. Idio vi guardi

Per Francesco e Lucha in Valenza

[Revés]

Francescho da Prato e compagni in Genova.

Conti

\section{2}

AD, filza 547, Valencia-Pisa. F. Datini y Luca del Sera a F. Datini. Doc. 600359

Génova, 18 de julio de 1394.

Extracto de cuenta de los albarelos comprados a Ametto moro en Manises y enviados a Pisa.

Al nome di Dio A dì 18 di luglo 1394.

Ponete a conto dare ci dobiate per IIII colli d'alberelli conperali per voi d'Ametto moro e man(dati) per Foghasotto in che fu [Signo].

XXXV alberelli mezani ${ }^{138}$

11. 1 s. 10

XXXII albereli grandi

11. 2 s. 8

CCLXXVI albereli picholi

11. 4 s. 15 d 8

Per II giare

11. (lac) s. 7

Per II boti

11. (lac)

Per invasalli

11. (lac) s. 2 d. 6

Per porto a mare e boti

11. (lac) s. 1 d. 2

Per sisa

11. (lac) s. 1 d. 6

Per general d. 6 per lb.

11. (lac) s. 4 d. 3

Per rifondare fondo

11. (lac) s. 3

Per caricare a mare e hostallagio dell'oste

11. (lac) s. 6

Per lelde di Panischola

11. (lac) s. 3

Per nostro dritto molti piu se ne so' spexi in bestie

per andare a Manizes a farli fare

11. (lac) s. 10

Somma tosto e spese

11. X s. XII d. I barza'

E cosi ponete a chonto. Idio vi ghuardi.

137 En B: se fato non Ë.

138 Tachado: grandi. 
Francesco e Lucha de Valenza.

[Revés]

Francescho da Prato e Mano d'Albizo in Pisa 1394. Da Valenza a dì 6 settembre.

Posto a livro B c. 24

Conto. 